\title{
Leaf Development and Expansion in Tea [Camellia sinensis (L.) Kuntze] and their Relationships with Thermal Time: A Case Study
}

\author{
H.A.S.L. Jayasinghe ${ }^{*}$, L.D.B. Suriyagoda ${ }^{1}$, A.S. Karunaratne ${ }^{2}$ and M.A. Wijeratne ${ }^{3}$ \\ Postgraduate Institute of Agriculture \\ University of Peradeniya \\ Sri Lanka
}

\begin{abstract}
Three field experiments were conducted to study the leaf and shoot expansion in tea [Camellia sinensis (L.) Kuntze] and their relationships with thermal time. The study site was Glen Alpine estate, Badulla, Sri Lanka located at an altitude of $1120 \mathrm{~m}$ above mean sea level (AMSL). The first experiment was carried out to develop a mathematical model to predict the area of an individual leaf and total leaf area of a harvestable shoot of widely grown tea cultivars namely, TRI 2025, TRI 2023, TRI 2043 and TRI 3035 in the Uva region. In the second experiment, the number of days required to initiate different leaves of a tea shoot of TRI 2025 was investigated. In the third experiment, the degree-days (thermal time) accumulated for producing different leaves and a harvestable tea shoot with three leaves of tea cultivar TRI 2025 were estimated. Stepwise regression resulted in a model with the product of leaf length and width to estimate the leaf area of a single tea leaf for all the evaluated cultivars with a high precision $\left(R^{2}=0.99\right)$. From the bud break, 128.5, 187.5, $234.5,295.5^{\circ} \mathrm{C}$ days were required to initiate the fish leaf, first normal leaf, second normal leaf and third normal leaf, respectively, of the tea cultivar TRI 2025. A harvestable tea shoot was produced after accumulating $392.5^{\circ} \mathrm{C}$ days by the cultivar TRI 2025.
\end{abstract}

Keywords: Leaf development, leaf expansion, tea, thermal time

\section{INTRODUCTION}

Tea [Camelia sinensis (L.) O. Kuntze] is a very important beverage crop in Sri Lanka and it is a sector where the country can take a lot of pride. This is mainly because of its prominence as a foreign exchange earner and the contribution to the country's Gross Domestic Production (GDP). Tea industry in Sri Lanka contributes $2 \%$ of the GDP while generating $11.2 \%$ of net foreign exchange earnings for the nation (Central Bank of Sri Lanka, 2012). Tea Leaves are the most important organ of this plant. The young, light green leaves, usually, the tip (bud) and the first two to three leaves, are harvested for tea production. Thus, leaf area (LA) of tea is an important element when studying the physiology of tea leaves, particularly when exploring the photosynthetic activity, distribution of radiation within the canopy, and water balance of the plant. For these reasons, it is important to establish a methodology to assess the parameters necessary to estimate LA, particularly under field conditions. Zenginbal et al. (2006) studied the LA expansion in tea using cultivars grown in Africa, and the applicability of their approach to Sri Lankan tea cultivars is not known. Even though

1 Department of Crop Science, Faculty of Agriculture, University of Peradeniya, Sri Lanka

2 Department of Export Agriculture, Faculty of Agricultural Sciences, Sabaragamuwa University of Sri Lanka

3 Tea Research Institute, Low Country Station, Rathnapura, Sri Lanka

* Corresponding author: sadeekaLJ@gmail.com 
there are quantitative relationships developed for the estimation and prediction of LA expansion in other crops, to the authors' knowledge, there are no reports concerning LA estimation of tea grown in Sri Lanka.

It is important to study the LA of different leaves in a tea shoot, and number of days taken to reach different leaf development stages of Sri Lankan tea cultivars, and this will provide the opportunity to estimate the LA expansion of harvestable shoots above the maintenance canopy and adjust field management. In many cases, field visits can be planned several days in advance when a field operation is required. However, it is difficult to predict leaf expansion and growth based on calendar days, because leaf initiation and expansion are highly temperature dependent (Ritchie and NeSmith, 1991).

Because of the dependency on temperature, leaf expansion rate varies with elevation and season/ month. For example, cool season can delay the time taken to produce a harvestable shoot from a bud. Therefore, growing degree days based on actual temperature is a simple and accurate method to predict the occurrence of a certain developmental stage. The duration of leaf development and leaf expansion rate of a tea shoot measured based on cumulative thermal time is a constant, and can be considered as a characteristic of a tea cultivar (Ben Haj Salah and Tardieu, 1995). Therefore, thermal time can be used to predict the developmental stage of a leaf and the relative expansion rate of any leaf accurately. Every phase of development requires a minimum accumulation of temperature duration. In effect, the plant senses the temperature every day and adds the average for that day to a running total up to the total required for completion of the stage. This running total is called cumulative thermal time or the heat sum for the phase and the thermal units are degree days $\left({ }^{\circ} \mathrm{Cd}\right)$. The number of days taken for unfolding of successive leaves ( 3 leaves+ bud) is called phyllochron. The approaches used to estimate the LA and thermal time are controversial for tea, and are mainly due to the interaction between genotype and environment (Muller et al., 2009). Therefore, the present study was carried out to develop simple relationships to estimate area of an individual tea leaf, and total LA of a harvestable shoot non-destructively, and correlate leaf and shoot expansion with thermal time.

\section{The objectives of the study were to;}

- $\quad$ predict LA of a single leaf of widely grown tea cultivars in Sri Lanka using leaf length (L) and width (W) measurements,

- determine the LA of an expanding shoot with time, and $\mathrm{L}$ and $\mathrm{W}$ of individual leaves,

- Estimate LA of a harvestable tea shoot using thermal time.

\section{MATERIALS AND METHODS}

This study was conducted at the Uva Wellassa University Glen Alpine estate, Badulla, Sri Lanka (latitude is 6.981 and longitude is 81.077) during mid January to June 2013. Elevation of the study location is $1120 \mathrm{~m}$ amsl and belongs to Agro-ecological region of IU3c. Four field grown cultivars of tea, TRI 2025, TRI 2023, TRI 3035 and TRI 2043 were used in three experiments. In the first experiment, measurements were taken to estimate the LA of an individual leaf and a pluckable shoot of TRI 2025, TRI 2023, TRI 3035 and TRI 2043. One hundred leaf samples at different developmental stages (i.e. mature leaves (maintenance foliage), fish leaves, first, second and third normal leaves and buds) from each cultivar were removed from different positions in the canopy. Immediately after detaching shoots from the 
bush, leaves were placed in plastic bags and transported to the laboratory. Leaf length (L) was measured from lamina tip to the point of intersection of the lamina along the midrib, while leaf width (W) was measured from end-to-end between the widest lobes of the lamina perpendicular to the lamina mid-rib. The actual area of each leaf (LA) was measured using grid method. Then the measured LA regressed with different independent variables, including $\mathrm{L}, \mathrm{W}, \mathrm{L}^{2}, \mathrm{~W}^{2}$, and the product $\mathrm{LW}$, and $\mathrm{L}^{2} \mathrm{~W}$ accordance with the equations developed by Zenginbal et al. (2006). The best models to explain the LA of different tea cultivars were determined through stepwise regression in SAS, based on the $\mathrm{R}^{2}$. Next, LA of twenty leaves from each cultivar at different growth stages was calculated using the grid method (i.e. observed LA) and regressed against the estimates derived through models (predicted) to test the accuracy of the model.

In the second experiment, field observations were made for TRI 2025 using $1 \mathrm{~m}^{2}$ sample size of plucking table with ten replicates which were tagged immediately after plucking. Length and width of individual leaves in a tea shoot (i.e. fish leaf, first, second and third normal leaf) were measured daily from randomly selected ten axillary buds while recording the number of days taken to initiate those leaves from the senescence of the scale leaf. Mean values of $\mathrm{L}$ and $\mathrm{W}$ were taken and the equation derived for TRI 2025 in the experiment 1 was used in estimating the LA at each day. Data analysis was done in SAS and MS-Excel software.

In the third experiment, increase in LA of a harvestable shoot (three leaves + bud) with thermal time (phyllochron) was estimated for TRI 2025. Non-destructive measurements of length (L) and width (W) measured in experiment 2 were used to estimate LA of an individual leaf in a tea shoot on a daily basis using the equation developed in experiment 1 . Daily minimum $\left(T_{\min }\right)$ and maximum $\left(T_{\max }\right)$ temperatures were obtained from the meteorological station at Badulla to calculate thermal time/ phyllochron $\left({ }^{\circ} \mathrm{C}\right.$ days). It is assumed to require a specific number of phyllochron for the completion of a particular stage of leaf development and after completion of particular leaf stage only shoot enters the next stage of leaf development. All measurements were taken until individual shoots reached their accepted harvesting stage. Then the relationships between the LA and cumulative thermal time were developed for each leaf type using regression analysis. Data were analyzed through MS-Excel and SAS software.

The accumulation of thermal time (TT) over the growing period was calculated using following equations (Robertson et al., 2002).

$$
\begin{aligned}
& T_{\text {mean }}=\frac{\left(T_{\max }+T_{\min }\right)}{2} \\
& \mathrm{TS}=0 \text {, If } T_{\text {mean }}<T_{\text {base }} \text { or } T_{\text {mean }}>T_{c e} \\
& \mathrm{TS}=T_{\text {mean }}-T_{\text {base }}, \text { If } T_{\text {base }}<\mathrm{T}_{\text {mean }}<T_{\text {opt }} \\
& \mathrm{TS}=\left[\left(T_{\text {opt }}-T_{\text {base }}\right) \times\left(1-\left(T_{\text {mean }}-T_{\text {opt }}\right) /\left(T_{c e^{-}} T_{\text {opt }}\right)\right], \text { If } T_{\text {opt }}<T_{\text {mean }}<T_{c e}\right. \\
& \mathrm{TT}=\sum \mathrm{TS} \\
& \text { where, } \\
& T_{\text {mean }} \quad=\text { daily mean temperature }\left({ }^{\circ} \mathrm{C}\right) \\
& T_{\min } \quad=\text { daily minimum temperature }\left({ }^{\circ} \mathrm{C}\right)
\end{aligned}
$$


$T_{\max } \quad=$ daily maximum temperature $\left({ }^{\circ} \mathrm{C}\right)$

$T_{\text {base }} \quad=$ base temperature $\left({ }^{\circ} \mathrm{C}\right)$

T optimum temperature $\left({ }^{\circ} \mathrm{C}\right)$

$T_{c e} \quad=$ ceiling temperature $\left({ }^{\circ} \mathrm{C}\right)$

$\mathrm{TS} \quad=$ thermal sum $\left({ }^{\circ} \mathrm{Cd}\right)$

TT $\quad=$ thermal time $\left({ }^{\circ} \mathrm{Cd}\right)$

It was considered that $T_{\text {base }} ; 12-13{ }^{\circ} \mathrm{C}$ (Carr and Stephens, 1992), $T_{\text {opt }} ; 22{ }^{\circ} \mathrm{C}$ (Amarathunga $e t$ al., 1999) and $T_{c e} ; 35-40{ }^{\circ} \mathrm{C}$ (Carr, 1972) for tea. Total precipitation was $415.8 \mathrm{~mm}$, mean radiation was $8.314 \mathrm{MJ} \mathrm{day}^{-1}$ and mean humidity was $78.4 \%$ at the experimental site during the research period.

\section{RESULTS AND DISCUSSION}

\section{Experiment 1}

Stepwise regression used for the determination of best fitting equations for the estimation of LA of TRI 2025, TRI 2023, TRI 2043 and TRI 3035 cultivars showed that most of the variation in LA was explained by the product of length and width $(\mathrm{L} \times \mathrm{W})($ Table 1$)$.

Table 1. Best fitted regression equations to estimate the leaf area (LA) as a function of leaf length (L) and width (W) for TRI 2025, TRI 2023, TRI 2043 and TRI 3035

\begin{tabular}{lcc}
\hline Tea Cultivar & Regression Equation & R-Square \\
\hline TRI 2025 & LA $=0.714 \times \mathrm{L} \times \mathrm{W}$ & 0.98 \\
TRI 2023 & $\mathrm{LA}=0.778 \times \mathrm{L} \times \mathrm{W}$ & 0.99 \\
TRI 2043 & $\mathrm{LA}=0.673 \times \mathrm{L} \times \mathrm{W}$ & 0.99 \\
TRI 3035 & $\mathrm{LA}=0.775 \times \mathrm{L} \times \mathrm{W}$ & 0.99 \\
For all the cultivars & $\mathrm{LA}=0.743 \times \mathrm{L} \times \mathrm{W}$ & 0.97 \\
\hline
\end{tabular}

Selected model for each cultivar, as given in the Table 1, could predict the actual (measured) LA very closely (Fig. 1). There was a very close relationship between the actual and predicted LA of cultivars tested. Therefore, these equations could be used for quantitative studies when estimating leaf area in tea. 

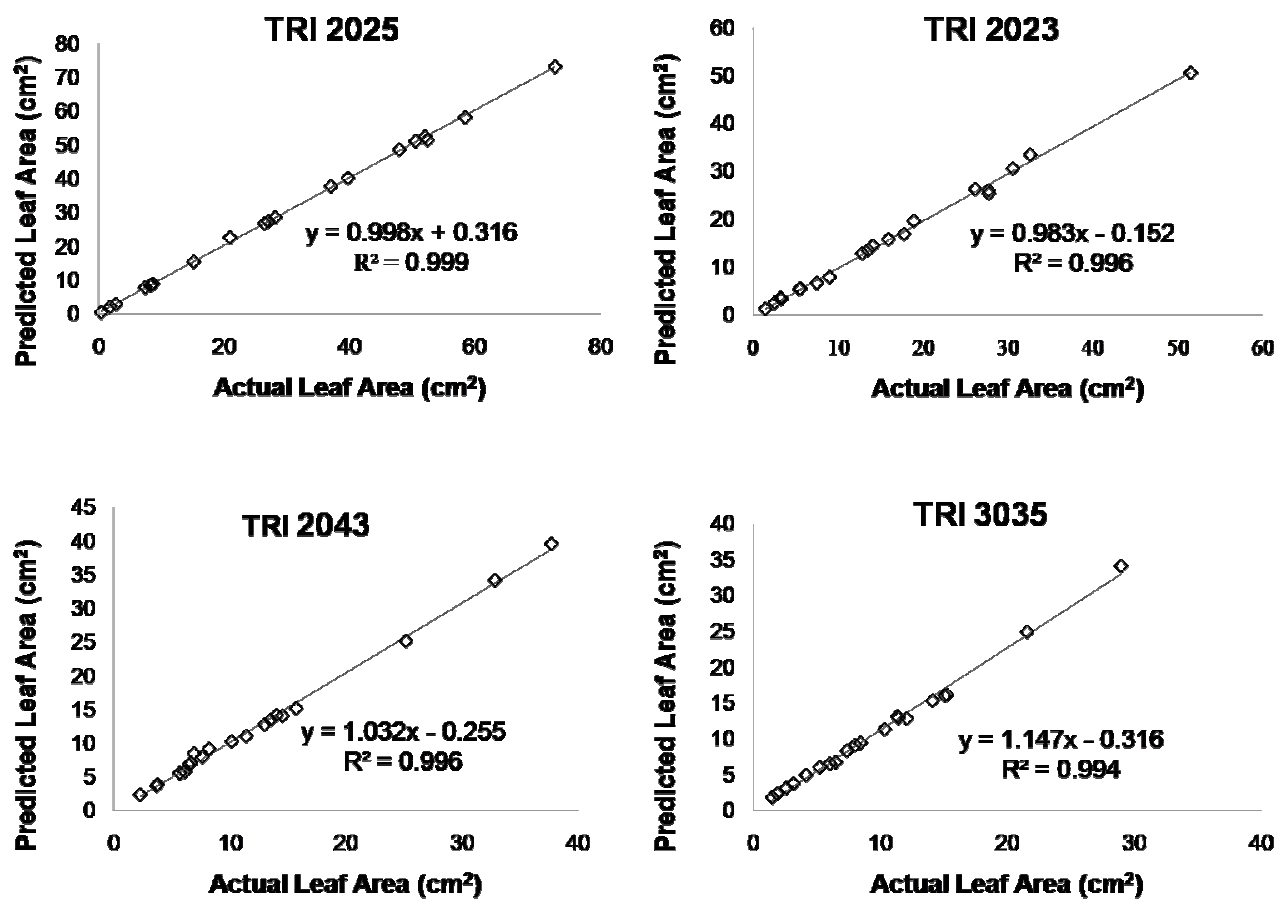

Fig. 1. Relationship between actual and predicted leaf area $\left(\mathrm{cm}^{2}\right)$ for TRI 2025 , TRI
2023, TRI 3035 and TRI 2043, note the differences in scales of X and Y axes.

Estimation of LA using leaf L and W is common (Smith and Kliewer, 1984; Elsner and Jubb, 1988; Zenginbal et al., 2006), because regression equations with leaf $\mathrm{L}$ and/or $\mathrm{W}$ are easy to measure, reliable and non-destructive.

Even though the leaf area prediction model by Zenginbal et al. (2006) used the L and W measurements, the model generated by them was complex (i.e. LA $=-0.66+(0.348 \times \mathrm{L})$ $\left(0.155 \times \mathrm{L}^{2}\right)-\left(0.133 \times \mathrm{W}^{2}\right)+[1.084 \times(\mathrm{L} \times \mathrm{W})]+\left[0.0062 \times\left(\mathrm{L}^{2} \times \mathrm{W}\right)\right]-\left[0.033 \times\left(\mathrm{W}^{2} \times \mathrm{C}\right)\right]$ where $\mathrm{LA}, \mathrm{W}, \mathrm{L}$ and $\mathrm{C}$ are for leaf area, leaf width, leaf length and cultivar, respectively. Moreover, parameter estimates from the models developed in the present study are different from those of Zenginbal et al. (2006) indicating that their approach and models are not suitable for estimating the LA of Sri Lankan tea cultivars used in the present study.

Present study demonstrated that the above equations (Table 1) with only the $\mathrm{L}$ and $\mathrm{W}$ measurements are acceptable for estimating LA of tea cultivars TRI 2023, TRI 2043, TRI 3035 and TRI 2025. As stated by Robbins and Pharr (1987), equation selection requires a balance between predictive qualities of the equation and the economy of including the least number of variables necessary to predict LA. Therefore, models generated in this study are in agreement with Robbins and Pharr (1987). 


\section{Experiment 2}

Time taken to initiate each successive leaf and LA are given in Fig. 2. As observed in experiment 2 after the scale leaves were fallen, 4 days were required to produce fish leaves, 11, 16 and 23 days to produce first, second and third normal leaf, respectively (Table 2).

Apart from the estimation of LA of an individual leaf in a tea shoot using L and $\mathrm{W}$ measurements as per equation derived in experiment 1, relationships between LA of individual leaves in a tea shoot and number of days from the senescence of scale leaves were also derived (Table 2). One can use number of days taken to initiate each leaf irrespective of their L and $\mathrm{W}$ measurement to estimate LA. This numbers of days/ calendar days are important for field staff to determine plucking rounds at a given location. However, this generic approach may not be practicable across locations as leaf initiation and expansion varies with daily temperature and other environmental conditions such as water stress and radiation intensity. Despite these limitations, this approach has practical importance when taking management decisions such as deciding plucking rounds at a given location.

Table 2. Best fitted regression equations to estimate the leaf area (LA) as a function of number of days (D) of TRI 2025

\begin{tabular}{lcll}
\hline $\begin{array}{l}\text { Stage leaf } \\
\text { development }\end{array}$ & $\begin{array}{c}\text { No. of days taken to } \\
\text { initiate each leaf from } \\
\text { the senescence of scale } \\
\text { leaves }\end{array}$ & \multicolumn{1}{c}{ Regression equation } & $\mathbf{R}^{\mathbf{2}}$ \\
\hline Fish leaf & 4 & $\mathrm{LA}=0.0008 \mathrm{D}^{2}+0.075 \mathrm{D}-0.163$ & 0.99 \\
$1^{\text {st }}$ normal leaf & 11 & $\mathrm{LA}=0.007 \mathrm{D}^{2}+0.008 \mathrm{D}-1.576$ & 0.99 \\
$2^{\text {nd }}$ normal leaf & 16 & $\mathrm{LA}=0.009 \mathrm{D}^{2}-0.2 \mathrm{D}+0.463$ & 0.99 \\
$3^{\text {rd }}$ normal leaf & 23 & $\mathrm{LA}=0.012 \mathrm{D}^{2}-0.58 \mathrm{D}+6.783$ & 0.99 \\
\hline
\end{tabular}

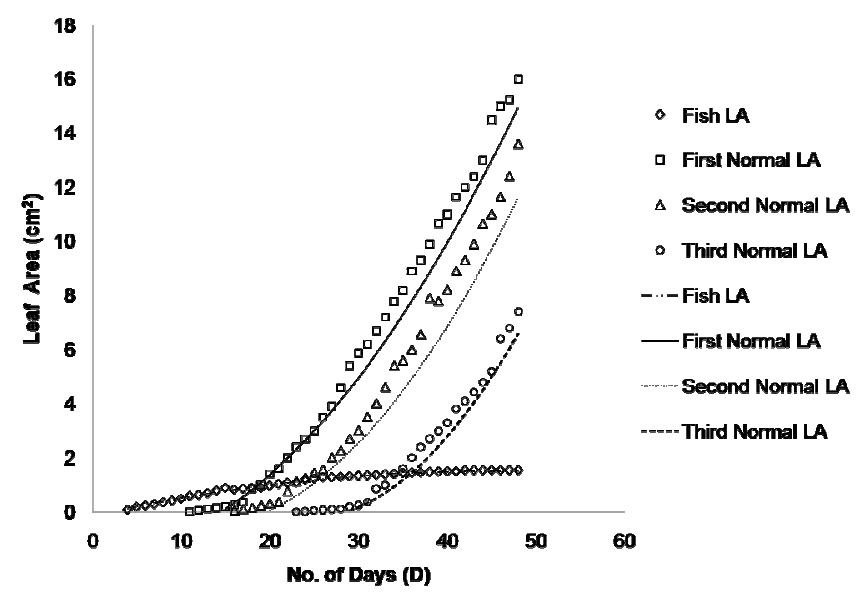

Fig. 2. Leaf Area (LA- $\mathrm{cm}^{2}$ ) of different individual leaves in a tea shoot of TRI 2025 from the base of a tea shoot with time (number of days), note: actual values are shown in symbols and estimated values are shown in lines. 
It is difficult to predict plant development and growth based on calendar days as variation in temperature affects these processes. At the time of harvesting of a tea shoot, leaves are at different growth stages. Therefore, LA of individual leaves varies with age. Fish leaf was very small compared to normal leaves and its leaf expansion rate was also very slow. All the normal leaves had a rapid leaf expansion rate $\left(0.25 \mathrm{~cm}^{2} /\right.$ day at $1120 \mathrm{~m}$ amsl).

\section{Experiment 3}

Results from the experiment 3 showed that $128.5{ }^{\circ} \mathrm{C}$ days were required to initiate the fish leaf after removal of apical dominancy by plucking. Similarly $187.5^{\circ} \mathrm{C}$ days were required to initiate the first normal leaf, $234.5^{\circ} \mathrm{C}$ days to initiate the second normal leaf and $295.5^{\circ} \mathrm{C}$ days to initiate the third normal leaf as shown in Fig. 3. To attain a harvestable tea shoot (three normal leaves and a bud) of cultivar of TRI $2025,392.5^{\circ} \mathrm{C}$ days were requited (Fig. 4). This is in agreement with the results of Wijeratne and Fordham, (1996). They have found that under average growing conditions in Sri Lanka, the number of degree-days accumulated for producing a harvestable shoot with three leaves of cultivar TRI 2025 is estimated to be 330-370 ${ }^{\circ} \mathrm{C}$ days in the high elevation (above $900 \mathrm{~m}$ ).

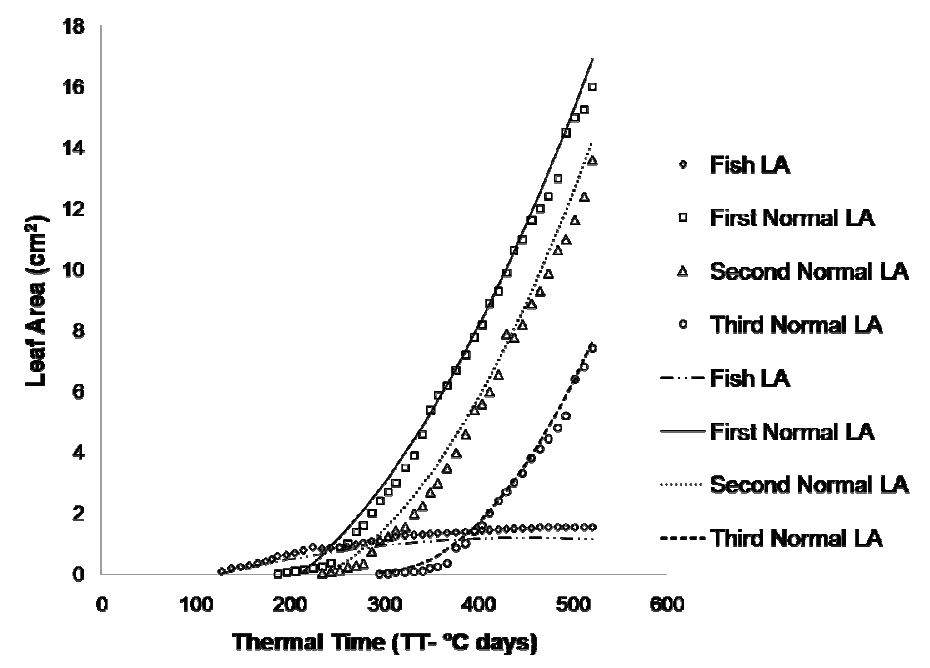

Fig. 3 Leaf area (LA- $\left.\mathrm{cm}^{2}\right)$ of an individual leaf in a harvestable shoots with thermal time, note: actual values are shown in symbols and estimated values are shown in lines.

In addition to the estimation of LA of an individual leaf with leaf development using $\mathrm{L}$ and $\mathrm{W}$ measurements, or using number of days, as per the equations derived in experiment 1 and 2 , relationships were developed with the LA of an individual leaf and cumulative thermal sum (Table 3). Results showed that when estimating LA cumulative thermal sum can be used as an alternative to $\mathrm{L}$ and $\mathrm{W}$ based or number of days based LA estimations. These thermal time requirements are important for managers and field staff to determine correct plucking rounds. 
Table 3. Best fitted regression equations to estimate the leaf area (LA) as a function of thermal time of TRI 2025

\begin{tabular}{lccc}
\hline $\begin{array}{l}\text { Stage shoot } \\
\text { development }\end{array}$ & $\begin{array}{c}\text { Thermal time } \\
\text { required to initiate } \\
\text { leaf after senescence } \\
\text { of scale } \\
\text { leaves }\left({ }^{\circ} \mathbf{C ~ d}\right)\end{array}$ & Regression equation & $\mathbf{R}^{\mathbf{2}}$ \\
\hline Fish leaf & 128.5 & $\mathrm{LA}=-1.1 \times 10^{-5} \times \mathrm{TT}^{2}-0.01 \times \mathrm{TT}-1.069$ & 0.99 \\
$1^{\text {st }}$ normal leaf & 187.5 & $\mathrm{LA}=9.5 \times 10^{-5} \times \mathrm{TT}^{2}-0.015 \times \mathrm{TT}-1.064$ & 0.99 \\
$2^{\text {nd }}$ normal leaf & 234.5 & $\mathrm{LA}=1.2 \times 10^{-4} \times \mathrm{TT}^{2}-0.041 \times \mathrm{TT}+2.987$ & 0.99 \\
$3^{\text {rd }}$ normal leaf & 295.5 & $\mathrm{LA}=1.5 \times 10^{-4} \times \mathrm{TT}^{2}-0.089 \times \mathrm{TT}+13.27$ & 0.99 \\
\hline
\end{tabular}

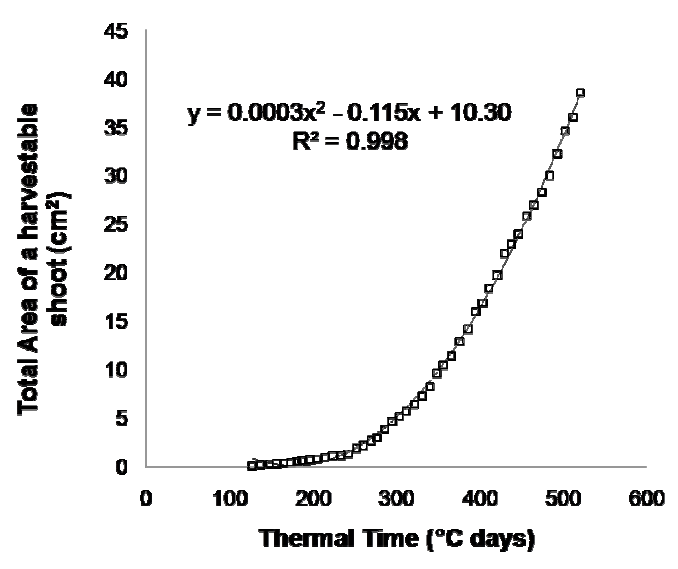

Fig. 4. Relationship between the total leaf area of a growing shoot with thermal time, note $128.5{ }^{\circ} \mathrm{C}$ days were required to initiate the fish leaf after removal of apical dominancy by plucking.

The temperature dependent LA expansion is used for the modelling and prediction of tea yield. Detailed studies have demonstrated that an accumulation of minimum number of degree- days is required for completion of most of the growth processes in plants. According to this concept, it is possible for tea growers to predict important harvesting policies such as plucking rounds for different periods of the year based on the temperature variation.

\section{CONCLUSIONS}

A simple model to predicting LA of a single leaf and a shoot, based on leaf length and width measurements was developed for widely cultivated tea cultivars (TRI 2023, TRI 2025, TRI 2043 and TRI 3035). After the scale leaves have fallen off, growing tea bud required 4, 11, 16 and 23 days to produce fish leaf, the first normal leaf, second normal leaf and the third normal leaf, respectively and bud was initiated after 27 days from the fish leaf initiation. In terms of degree days $128.5,187.5,234.5,295.5$ and $392.5^{\circ} \mathrm{C}$ days were required to initiate, 
fish leaf, the first, second and the third normal leaf, respectively after removal of apical dominance by plucking.

\section{ACKNOWLEDGEMENT}

Authors thank all the technical staff of the Biology Laboratory, Uva Wellassa University for their assistance during the experiments, and to the superintendents of Glen Alpin estate for their permission to obtain tea leaf samples. Research Facilitation Fund (RFF) at the Postgraduate Institute of Agriculture, University of Peradeniya is also greatly acknowledged.

\section{REFERENCES}

Amarathunga, M.K.S.L.D., Jayaratne, K.P.S.C. and Wijeratne, M.A. (1999). Effect of ambient temperature and evaporation on yield of tea in Sri Lanka. Proceedings of $55^{\text {th }}$ Annual sessions, Part 1, SLAAS, Colombo, Sri Lanka. 99 - 100.

Ben Haj Salash, H. and Tardieu, F. (1995). Temperature affects expansion rate of maize leaves without change in spatial distribution of cell length. Analysis of the coordination between cell division and cell expansion. Plant Physiology. 109, 861 - 870.

Carr, M.K.V. (1972). The climatic requirements of the tea plant: A review. Experimental Agriculture. 8, 1 - 14.

Carr, M.K.V. and Stephens, W. (1992). Climate, weather and the yield of tea. In: Willson KC, Clifford MN (eds), Tea: Cultivation to Consumption, 87-135. Chapman and Hall, London.

Central Bank of Sri Lanka (2011), Sri Lanka Socio-Economic Data 2011. Vol. XXXIV

Elsner, E.A. and Jubb, G.L. (1988). Leaf area estimation of Concord grape leaves from simple linear measurements. Am. Journal of Enology and Viticulture. 39, 95 - 97.

Muller, D., Kuemmerle, T., Rusu, M., Griffiths, P. (2009). Lost in transition: determinants of post-socialist cropland abandonment in Romania. Journal. Land Use Sciences. 4, 109 - 129.

Ritchie, J.T, and NeSmith, D.S. (1991).Temperature and crop development. Modeling plant and soil systems. Madison. 5 - 29.

Robbins, S.N. and Pharr, D.M. (1987). Leaf area prediction models for cucumber linear measurements. Horticultural Sciences. 22, 1264 - 1266.

Robertson, M.J., Carberry, P.S., Huth, N.I., Turpin, J.E., Probert, M.E., Poulton, P.L., Bell, M., Wright, G.C., Yeates, S.J., Brinsmead, R.B., (2002). Simulation of growth and development of diverse legume species in APSIM. Australian Journal of Agricultural Research 53, 429 - 446.

Smith, R.J. and Kliewer, K.W. (1984). Estimation of thompson seedless grapevine leaf area. Am. Journal of Enology and Viticulture. 35, 16- 22. 
Wijeratne, M.A. and Fordham, R. (1996). Effect of climatic factors on the growth of tea (Camelia sinensis L.) in the low country wet zone of Sri Lanka. Sri Lanka Journal of Tea Science. 46, 21 - 34.

Wijeratne, M.A. (2001). Shoot growth and Harvesting of tea, Tea Research Institute of Sri Lanka.

Zenginbal, H. Ozcan, M., Uzun, S. and Cuneyt, C. (2006). Non-destructive estimation of leaf area in tea (Camelia sinensis). Research Journal of Botany. 1, 46 - 51. 